\title{
HOW MICE CAN REVEAL THE SECRETS OF RARE DISEASES
}

EVEN THOUGH MEDICINE HAS ADVANCED A LOT OVER THE LAST CENTURY, THERE ARE STILL MANY UNANSWERED QUESTIONS. THIS IS ESPECIALLY TRUE FOR RARE DISEASES. DR KEVIN MARCHBANK OF NEWCASTLE UNIVERSITY IS USING MOUSE MODELS TO INVESTIGATE THE GENETICS BEHIND TWO RARE DISEASES THAT AFFECT THE KIDNEYS - AND HIS FINDINGS COULD BE KEY TO DEVELOPING TREATMENTS

\section{TALKING LIKE A BI으으GIST}

Medical terminology can seem complicated, but in fact has quite simple meanings. Here are some key terms relating to two rare diseases, which Dr Kevin Marchbank is investigating: aHUS and C3G:

aHUS

Atypical: Out of the ordinary

Haemolytic: Breakdown of red blood cells

Uraemic: High levels of urea in the blood (urea is a waste product that should normally be transferred into the urine by the kidneys)

Syndrome: A group of symptoms that suggest something is wrong

\section{C3G}

C3: An important protein in the immune system

Glomerulopathy: A disease that affects a part of the kidneys, causing them to malfunction

\section{COMPLEMENT}

Complement is a chain of enzymes whose activation eventually results in the disruption of cell membranes and the destruction of cells or invading microorganisms. Complement is an essential part of the body's defence system:

http://www.biologydiscussion.com/immunology/complement-system/complement-systemdefinition-functions-and-components/61928
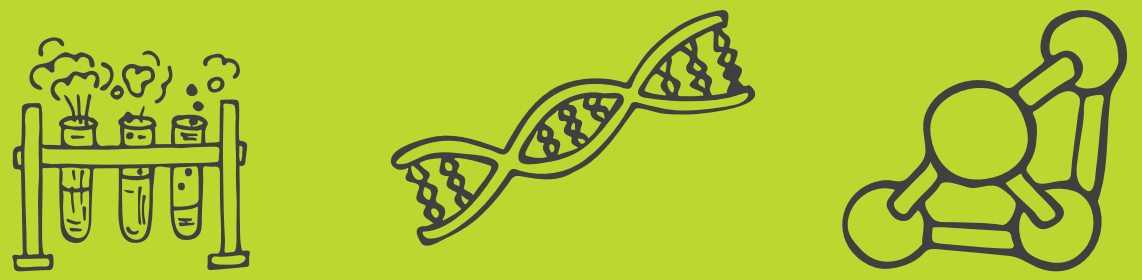

There are between 6,000 and 8,000

known rare diseases. Although they are rare, altogether they affect about $6 \%$ of the population at some point in their lives. Many of these diseases are genetic, meaning they are triggered by mistakes in a sufferer's DNA. Understanding the causes of rare diseases not only save lives, but also helps researchers learn more about how our genes and bodies work.

Atypical haemolytic uraemic syndrome (aHUS) and C3 glomerulopathy (C3G) are two examples of rare diseases. Dr Kevin Marchbank, a complement biologist in Newcastle University's Translational and Clinical Research Institute (Faculty of Medical Sciences) and the National Renal Complement Therapeutics Centre (NRCTC, $\mathrm{RVI}$, Newcastle), is investigating their root causes.

WHAT ARE AHUS AND C3G? aHUS and C3G mainly affect the kidneys. The kidneys are essential organs for removing waste products from the blood and controlling our fluids. Malfunctions can be extremely serious. Although aHUS and C3G are rare - less than one in a million people develop either disease each year - they are not to be taken lightly. "Both aHUS and C3G can affect young people," says Kevin. "There are around 100 young people in the UK dealing with these diseases right now." 


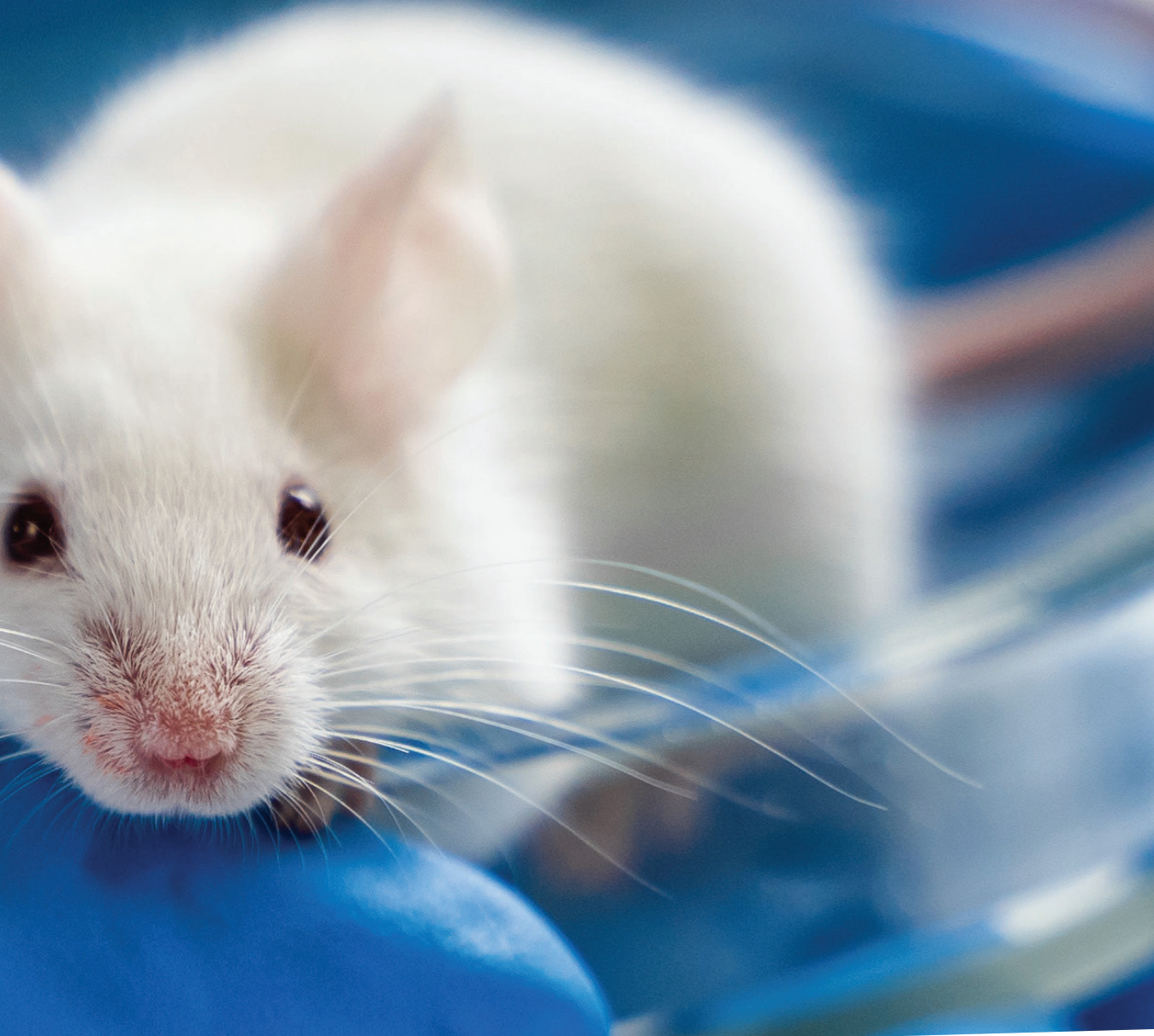

Both diseases involve the complement system, which is a part of the immune system that enhances (complements) the body's ability to prevent or fight off infection. It is when this system behaves in the wrong way that trouble arises. "In the military, there is a term called friendly fire, when a soldier is hit by his own army's weapons," explains Kevin. "It is the same in the body. In aHUS and C3G, the complement system starts to attack our own tissues. The kidneys seem to be particularly vulnerable to attack." When the immune system attacks the kidneys, it can stop them functioning properly. This leads to all sorts of problems throughout the body, including possible kidney failure.

WHY FOCUS ON RARE DISEASES, RATHER THAN COMMON ONES?

Investigating rare diseases is a powerful way to learn more about the body's processes. "By treating any disease, we move a step closer to treating all disease," says Kevin. "Rare diseases are often down to one thing going wrong," explains Kevin. "By working out what it is and fixing it, we can apply this knowledge to more complex diseases. For instance, the treatment of aHUS and C3G has also led to treatments for eye diseases."

Since many rare diseases are also genetic, studying them can help us learn more about our genes. The process of how DNA affects

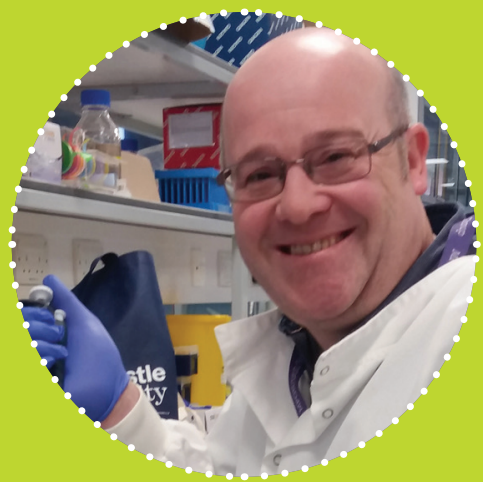

\section{DR KEVIN MARCHBANK}

Reader in Complement Biology Translational and Clinical Research Faculty of Medical Sciences and School of Biomedical

Nutritional and Sport Sciences Newcastle University UK

-..........

FIELD OF RESEARCH

Complement Biology

\section{RESEARCH PROJECT}

Using mouse models to investigate the causes and potential treatments of two rare diseases that affect the kidneys.

body functions is incredibly complex, and often difficult to understand. By investigating what goes wrong in the body when genes have the wrong coding, scientists can piece together cause and effect.

\section{WHERE DOES THIS RESEARCH} TAKE PLACE?

Kevin oversees the autoimmune research and analysis at the NRCTC. Autoimmunity is when the immune system starts to attack rather than protect the body's tissues or organs. Renal describes things that relate to the kidneys. The NRCTC is a base for analysing the relationship between the kidneys and the complement system. Excitingly, it is at the NRCTC that Kevin and his team can put their findings into practice. For example, the NRCTC manages the prescription of a drug called Eculizumab. "This amazing drug can block the destructive firepower of the complement system," explains Kevin.

The researchers meet patients in person to prescribe Eculizumab if needed and ensure that the treatment is working.

"The team at the NRCTC covers all aspects of modern medicine, from fundamental research right through to its application," says Kevin. "We work with cutting-edge drugs. Everybody working there also needs strong science and communication skills because the NRCTC travels the country giving

\section{FONDERS}

United Kingdom Research and Innovation (UKRI), Kidney Research UK/ Northern

Counties Kidney Research Fund

roadshows, improving patients' and relatives' understanding of their diseases."

If you're feeling inspired by the work of biologists like Kevin, take a look at this video about Ros Ford. She shares her story about living with aHUS and how research into the disease has helped her do the things she loves doing: https://www.youtube.com/ watch?v=k3TeJdM1W6w\&feature=youtu.be

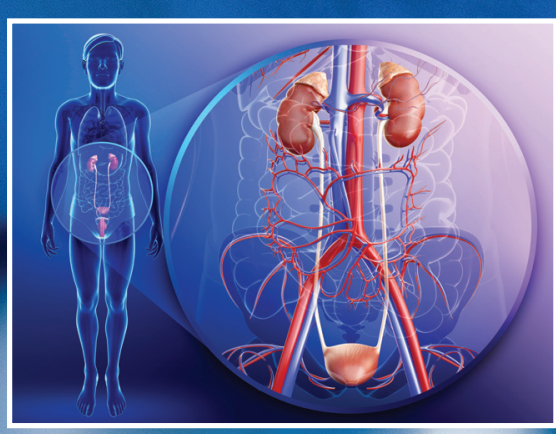

Anatomy of kidneys in a male human body. 
Mice are often used in laboratory experiments to investigate diseases. They are a useful 'model organism' because much of their biology is similar to people, as Kevin explains: "We can model human diseases on mice. This can be through genetic modification or testing their responses to a certain drug or vaccine." Mice have quite short lifespans and are easy to keep in laboratory conditions, so it is much more straightforward to run experiments using mice rather than people. Mouse models are also usually considered more ethical.

CAN MICE MODELS REALLY HELP US FIND TREATMENTS FOR HUMANS?

"Mice are different to people, of course, but much of their immune system is highly similar to ours. This is especially true for the parts of the complement system involved in aHUS and C3G," says Kevin. Using mice ensures that potential dangers of new drugs are discovered before they put human patients' health at risk. Development of any drug involves a series of rigorous tests, and animal testing is often a key step in the process. If all has gone well in these tests, then clinical trials involving human patients usually follow. Using mice first means that most (or even all) side-effects or other outcomes are known before the drug is administered to humans. This ensures that dangers to patients are kept to an absolute minimum.

\section{WHAT IS AN EXAMPLE OF A MOUSE MODEL?}

Genetic diseases are caused by mistakes in our DNA, which is what makes up our genes. DNA sequences tell the body to build particular proteins. It does this by providing codes for sequences of amino acids, the 'building blocks' that make up proteins. "At NRCTC, we investigated a family afflicted by aHUS," says Kevin. "We found a single amino acid change that was different to what most people have. This was in C3, the central protein of the complement system." An error had occurred in the family's genetic code, which can be passed on to future generations. Now the researchers can use this information to genetically modify mice to express the same amino acid change. The line of mice with this change, which will lead to them suffering from aHUS, is known as a mouse model.

This mouse model proved very useful. "Amazingly, this one amino acid change can lead to aHUS but can also be effectively treated with drugs like Eculizumab," says Kevin. "We also established that this treatment is unlikely to make patients suffer from C3G instead." It is mouse models like this that have ultimately allowed sufferers of rare diseases to receive treatment and improve their quality of life.

\section{WHAT ABOUT CONCERNS OVER}

\section{CRUELTY TO ANIMALS?}

Experiments on animals are often controversial, as they can cause pain and suffering to the animals involved. "Every day I weigh up the worth of our experiments," says Kevin. "I believe that it is also cruel not to help children suffering from diseases, but it is always a tough question." Experiments on animals are carefully regulated and scrutinised to make sure suffering is kept to a minimum, particularly in the UK.

Experiments on animals help scientists make sure that drugs and other procedures do not pose a risk to patients' health. Research innovations, such as artificially created organic tissue and advanced computer modelling, mean that animal testing should become less necessary over the next few decades.

\section{HOW T을 BECOME A (COMPLEMENT) BIOLOGIST}

- Kevin says that the NRCTC offers work experience and internships. The centre's contact details can be found here: http://www.atypicalhus.co.uk/ contact-us/

- There are a number of pathways that can lead to a career in complement biology or related fields within the life sciences. An undergraduate degree in biology is the most obvious starting point, but degrees in related subjects such as chemistry and medicine are also good choices.

- Many science organisations offer work experience in laboratories specifically for A-level students. The MRC Clinical Sciences Centre, GlaxoSmithKline and the Wellcome Trust Sanger Institute are among them. The Royal Society of Biology has a good list: https://www.rsb.org.uk/ careers-and-cpd/careers/work-experience

- According to the National Careers Service UK, experienced biologists can earn up to $£ 70,000$.

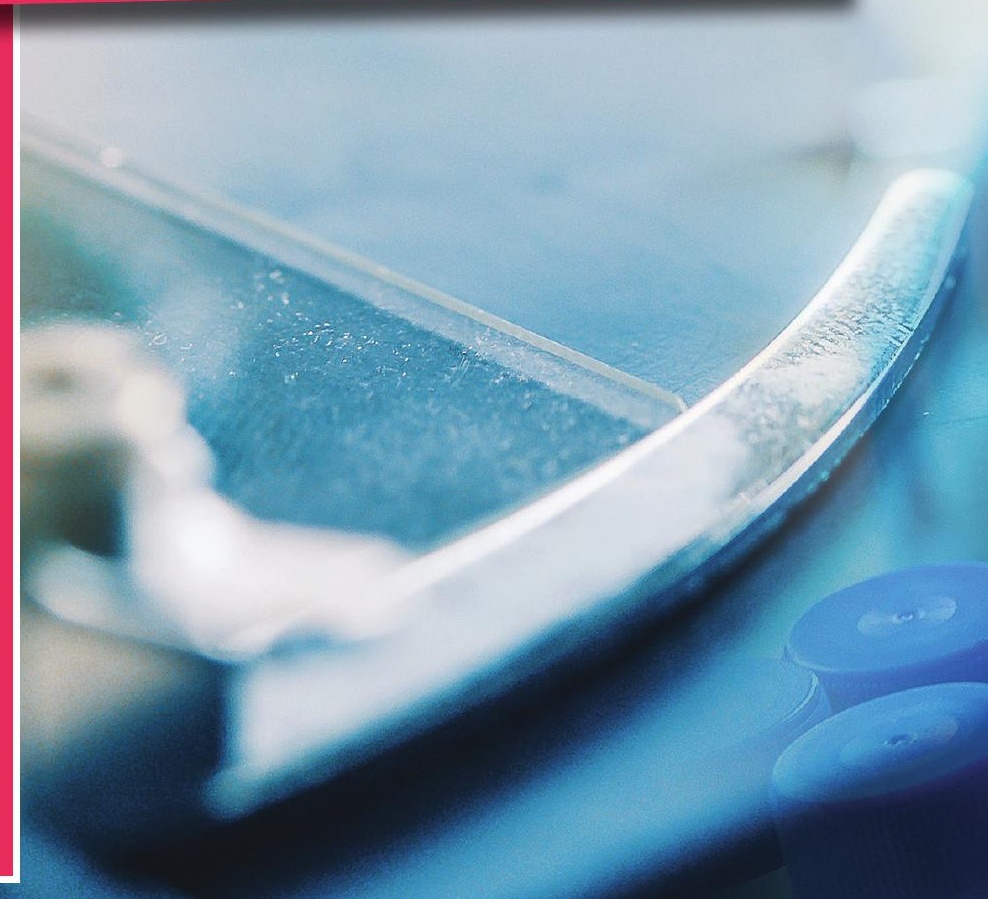




\section{WHAT DID YOU WANT TO BE WHEN} YOU WERE YOUNGER?

I wanted to be a fighter pilot when I was very young, but poor eyesight meant that wasn't a possibility. Next, I decided to be a farmer, but I soon realised how hard that way of life would be, even though I love the outdoors. Then I wanted to become an explorer and travel the world.

\section{WHAT INSPIRED YOU TO \\ STUDY BIOLOGY?}

I have always loved nature and building things. I once made a lawnmower using parts of a washing machine! I was a bit of a geek at secondary school and I suppose it was clear that science was my thing. Biology always came naturally to me. My dad and I used to watch loads of natural history TV programmes; I was a big fan of Jacques
Cousteau. I loved experiments, particularly chemistry - who doesn't love an explosion? I also had a teacher called Dr Thornton who encouraged me to become a scientist. It was him and my biology teachers that suggested I go to university, for which I am very thankful.

WHAT ADVICE WOULD YOU GIVE YOUR YOUNGER SELF?

I have two golden rules: never give up and believe in your skillset. Following these rules has done me proud. I think I was lucky to just be able to follow my heart. I chose my PhD because I loved science and didn't worry about the money too much. All that just followed. So, I would tell myself, if you have a passion for the research and belief in the journey, you will get there.
WHAT DO YOU LOVE MOST ABOUT YOUR WORK?

I have the opportunity to make a difference to people's lives. I am a bit sentimental, but you must admit that having the chance to improve hundreds (if not thousands) of people's wellbeing is very cool.

\section{WHAT MOTIVATES YOU?}

I love science. It is constantly changing and constantly challenging, and never gets dull. As a senior scientist I am not able to perform experiments myself as much as I used to, but I get to experience that through my colleagues whom I advise. We have a great team working together to solve issues to make the world a better place. This keeps me in the lab much longer than my family would like, that's for sure!

\section{KEVIN'S TOP TIPS}

- It's never too late to get into science, but it's easier if you start earlier. I have taught people with degrees in English and history, and if they have the passion for science, they can make the transition. Biology and chemistry A-levels were all I needed for my degree, but maths, statistics and physics are also useful.

- Figure out what problem you want to solve and then go after it with an absolute passion.

- Persistence, innovation, a sense of fun and also humility are important qualities in a scientist. Develop all these, and you can't go wrong.

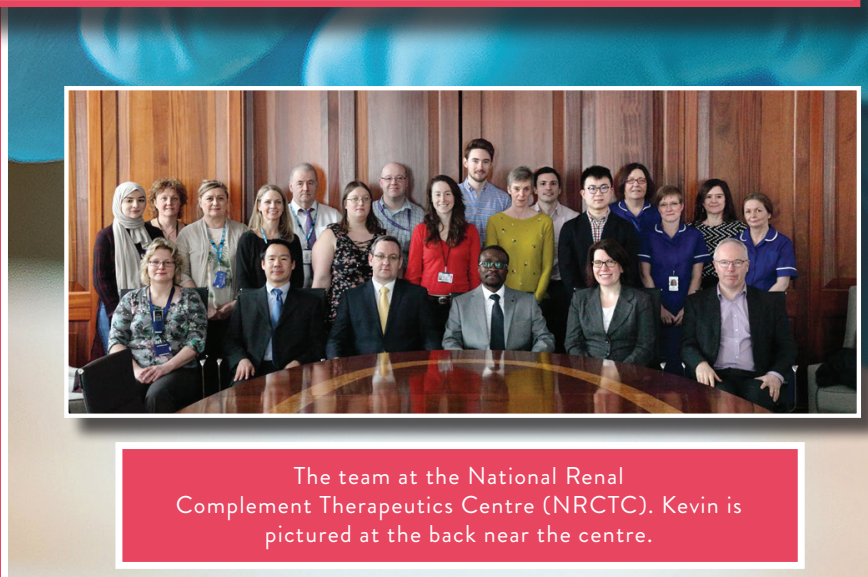

\section{PATHWAY FR으 SCHOㅇ T으 BI응GIST}

GCSEs at grades 9 to 4 ( $A^{*}$ to $C$ ), or equivalent, including English, maths and science

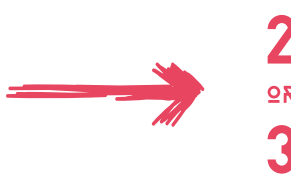

A-levels, or equivalent, including biology for a degree

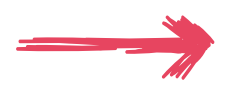

A degree in biology, biological science, ecology,

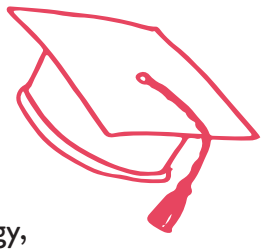
marine biology 